American Journal of Environmental Sciences 6 (6): 477-483, 2010

ISSN 1553-345X

(C) 2010 Science Publications

\title{
Optimization of Hydraulic Parameters of Iranshahr Alluvial Aquifer
}

\author{
${ }^{1}$ Jafar Rahnama-Rad, ${ }^{2}$ Mohammad Yaghoub Bavali and ${ }^{3}$ Reza Derakhshani \\ ${ }^{1}$ Department of Geology, Islamic Azad University, Zahedan, Iran \\ ${ }^{2}$ Water Authority of Sistan and Baluchestan, Zahedan, Iran \\ ${ }^{3}$ Department of Geology, Shahid Bahonar University, Kerman, Iran
}

\begin{abstract}
Problem statement: The Iranshahr aquifer consists of an unconfined layer. We simulated groundwater flow of the Iranshahr aquifer in a conceptual model. This model is a suitable tool for management of groundwater system and would also be effective when applied in other countries. Approach: In this study, we constructed the conceptual model of Iranshahr aquifer, which is important and applicable in environmental studies. We used the automatic parameter estimation method and hydraulic head observation through calibration in order to identify the best parameter values. During the calibration, the optimized values of the parameters obtained. 24 parameters estimated by means of regression and the rest remaining unestimated parameters optimized using the trial-and-error method.

Results: The results of the model show a good fit between observation and simulated values. Automated calibration procedure estimated the hydraulic parameters of the aquifer. Conclusion: The optimized values and the zonation of the hydraulic parameters of the aquifer showed the best areas for developing and extracting groundwater from the aquifer taking the optimized hydraulics values into account.
\end{abstract}

Key words: Hydraulic parameters, automated calibration, anonymous, heterogeneous media, Iranshahr aquifer, conceptual model, groundwater systems, watershed area

\section{INTRODUCTION}

Mathematical models have been considered as suitable tools for management of groundwater systems (Donaldson and Schnabel, 1987; Tiedeman et al., 2004; Alipour and Derakhshani, 2010). Ground water models have been applied for different purposes (Derakhshani and Alipour, 2010; Cooley, 2004; D'Agnese et al., 2002; Anderson and Woessner, 1992; Al-Rababa, 2005; Naeser, 2005; Rahmat et al., 2010; Abbasnejad and Derakhshani, 2010; Opafunso et al., 2009; Jolgaf et al., 2008; Suhail et al., 2010). Construction and development of a groundwater model has been based on the modeling protocol (Anderson and Woessner, 1992). This protocol consists of some steps in which preparing for conceptual model, calibration and verification are the most important steps. During calibration, model input such as system geometry, properties, initial and boundary conditions and stresses are changed so that the model output matches the related measured values (Hill and Tiedeman, 2007).

Two methods are commonly used for identification of mode parameters through calibration: trial and error method and automatic parameter estimation (Solomatine et al., 1999; Madsen, 2003). In the trial and error method, parameter values are assigned to the each node of the model and during the calibration these values has been adjusted, until the simulated values (head, discharge,...) are close to the observed ones.

In the automatic parameter estimation, the comparison between simulated values and observed ones (objective function) is accomplished quantitatively and the best parameter values that produce the smallest value of the objective function has been achieved (Hill and Tiedeman, 2007; Abbaspour et al., 2001).

There are many benefits and capabilities with the automatic parameter estimation that help modelers for complex systems (Hill and Tiedeman, 2007; Abbaspour et al., 2001; Poeter and Hill, 1997). Some of these benefits according to (Hill and Tiedeman, 2007; Abbaspour et al., 2001) are:

- Clear determination of parameter values that produce the best possible fit to the available observations

- Graphical analysis and diagnostic that quantify the quality of calibration

- Inferential statistics that quantify the reliability of parameter estimation and predictions

- Other evaluations of uncertainties

Corresponding Author: Jafar Rahnama-Rad, Department of Geology, Faculty of Basic Sciences, Islamic Azad University, Zahedan Branch, Zahedan, I.R. Iran Tel/ Fax: +985412419426 
MODFLOW-2000 (Harbaugh et al., 2000; Hill et al., 2000), UCODE-2005 and PEST are the most commonly used computer programs that simulate three dimensional groundwater flow using finite difference method (Gardner, 2009). All of these codes perform inverse modeling, posed as a parameter-estimation problem, by calculating parameter values that minimize a weighted least-square objective function using nonlinear regression (Hill and Tiedeman, 2007).

\section{MATERIALS AND METHODS}

A modeling protocol, which is exerted from (Anderson and Woessner, 1992), for groundwater model construction is pursued more or less to construct a model for this study. The main steps to identify the hydraulic parameters are:

- Development of a conceptual model of the system: Hydrostratigraphic units are identified in this step. Field data are assembled including information on the water balance and data needed to assign to aquifer parameters and hydrological stresses

- Model design: The conceptual model is put into form suitable for modeling. This step includes design of the grid, selecting time step, setting boundary and initial condition and preliminary selection of values for aquifer parameters and hydrologic stresses

- Calibration: The purpose of calibration is to put the model in a position that can reproduce

- Observation values: Calibration has been carried out by using automated parameter estimation code; MODFLOW 2000

- Only hydraulic head observation has been used through calibration

- Sensitivity analysis: To establish the effect of uncertainty on the calibrated model is to put the model in a position that can reproduce

\section{RESULTS}

The study area, Iranshahr watershed, is located in the Sistan and Baluchistan province, in the southeast of Iran and southeast of Jazmurian depression (Fig. 1). This area is located in the north of Makran (Farhoudi and Karig, 1977) and in the east of Zagros mountain Range (Rahnama-Rad et al., 2008; Stocklin et al., 1972). Iranshahr city is the main population center in the area. The watershed area is $8018 \mathrm{~km}^{2}$, of which $6882 \mathrm{~km}^{2}$ are in sharp reliefs against the $1136 \mathrm{~km}^{2}$ of alluvial plains. The highest point of the area has an elevation of 2720 $\mathrm{m}$ to the northeast and the lowest point has an elevation of $500 \mathrm{~m}$ to the west near the Bampour River.

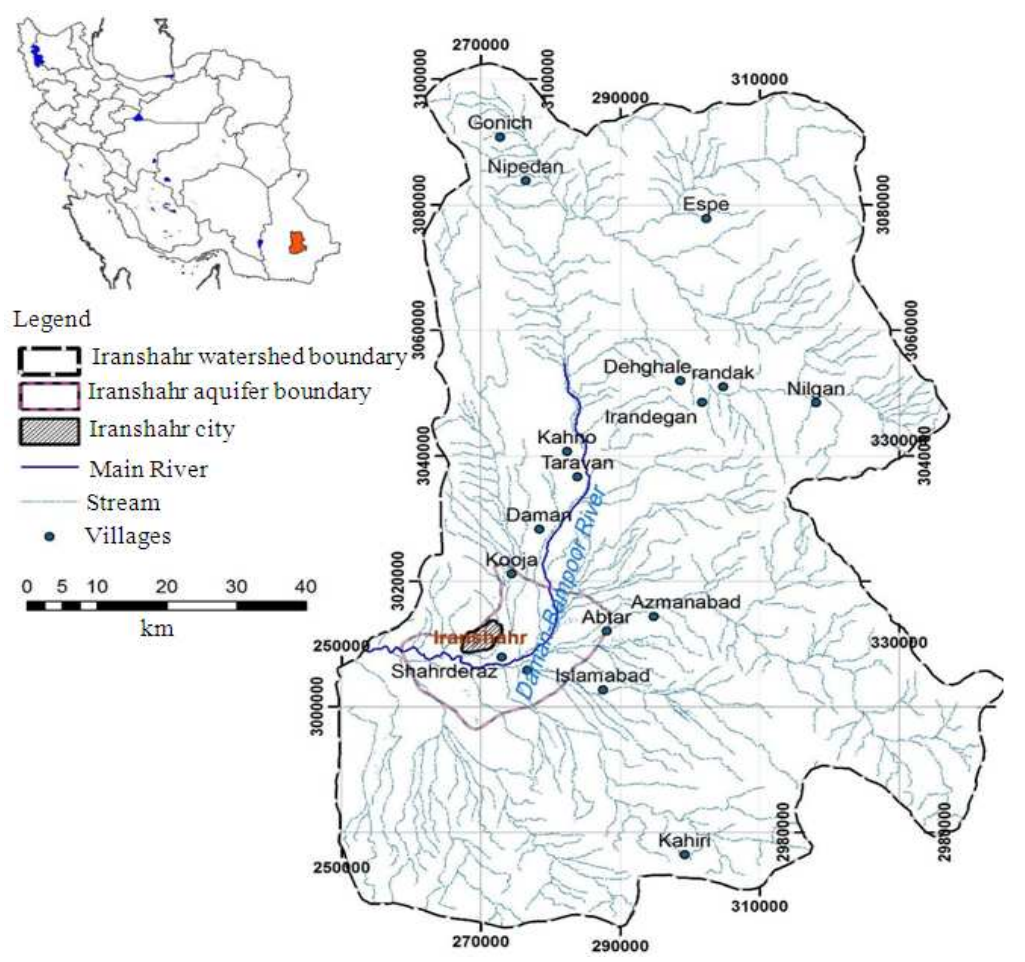

Fig. 1: Location map of the Iranshahr watershed and aquifers 
Am. J. Environ. Sci., 6 (6): 477-483, 2010

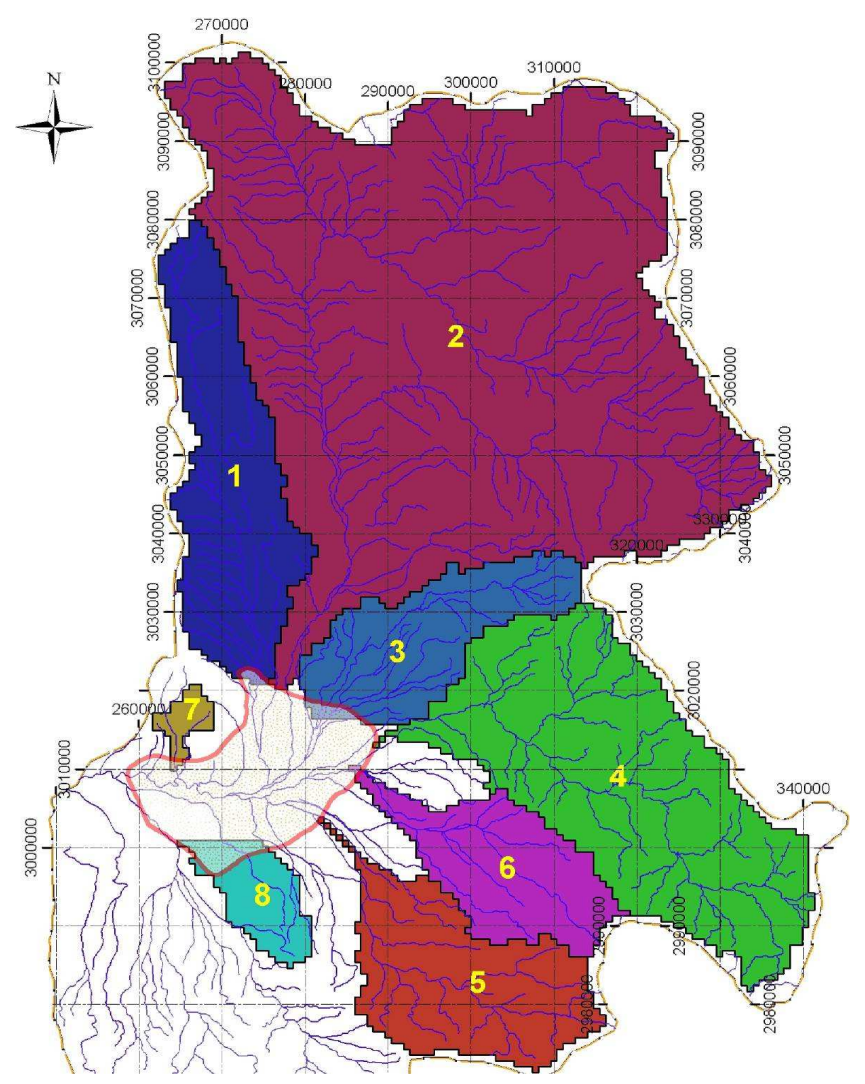

Fig. 2: Iranshahr watershed subbasins

Table 1: Properties of Iranshahr watershed subbasins

\begin{tabular}{lllr}
\hline Subbasin & Average elevation $(\mathrm{m})$ & Perimeter $(\mathrm{m})$ & \multicolumn{1}{c}{ Area $\left(\mathrm{m}^{2}\right)$} \\
\hline 1 & 1061.1 & 171338.5 & 589057335.8 \\
2 & 1300.0 & 378126.3 & 3293812269.4 \\
3 & 880.0 & 121118.6 & 387250655.9 \\
4 & 1042.8 & 214173.1 & 1091392341.6 \\
5 & 1230.7 & 149182.6 & 493608230.5 \\
6 & 1040.0 & 128503.9 & 352888978.0 \\
7 & 600.0 & 38403.5 & 38179642.1 \\
8 & 677.3 & 66467.5 & 138537558.6 \\
\hline
\end{tabular}

The geological formations consist of sedimentary (Hadavi, 2002) and igneous rocks (Emami, 2000) in the north and south of the plain respectively (McCall, 1985; Romanko, 2006; Hill, 1998). In the southeast, the lithology consists of about 8 kilometers thick Bazman granite. Most of the geologic formations around the Iranshahr plain are impermeable.

The climate of the area is arid and the average of precipitation, based on the three weather stations in the watershed, is $103.5 \mathrm{~mm}$ (recording period of 19892007). High temperature in the watershed causes a high evaporation. Average annual evaporation of the plain is $3295 \mathrm{~mm}$ (recording period of 1982-2007). Most of the rainfall is during January and February.
The main surface water features in the watershed are seasonal rivers (Daman and Saradan) that drain the runoff from north, east and southeast. The Bampour perennial river has been drained from the aquifer (Fig. 1). Iranshahr watershed has eight subbasins that drain the surface water to the plain and aquifer surface. The main subbasins are Daman (number 2) and Saradan (number 4) (Fig. 2). Table 1 shows the properties of these subbasins.

Iranshahr aquifer is within the area bounded by latitude $60^{\circ} 25^{\prime}-61^{\circ} 25^{\prime} \mathrm{N}$ and longitude $52^{\circ} 53^{\prime}-53^{\circ} 8^{\prime}$ E. Groundwater flow direction is the same as surface water, i.e. from north, east and southeast to the west and discharge to Bampour River (Fig. 3). The most important sources of the aquifer's recharge are the direct recharge from precipitation and especially from subsurface flow of seasonal Daman and Saradan rivers (Fig. 3). Returned water from wastewater and irrigation also recharge the groundwater. Groundwater is extracting from 260 shallow and deep wells and 12 Qanat strings (underground artificial channels) in the aquifer area, mostly for agricultural and drinking use. Depths of the wells vary between 10-120 m. 


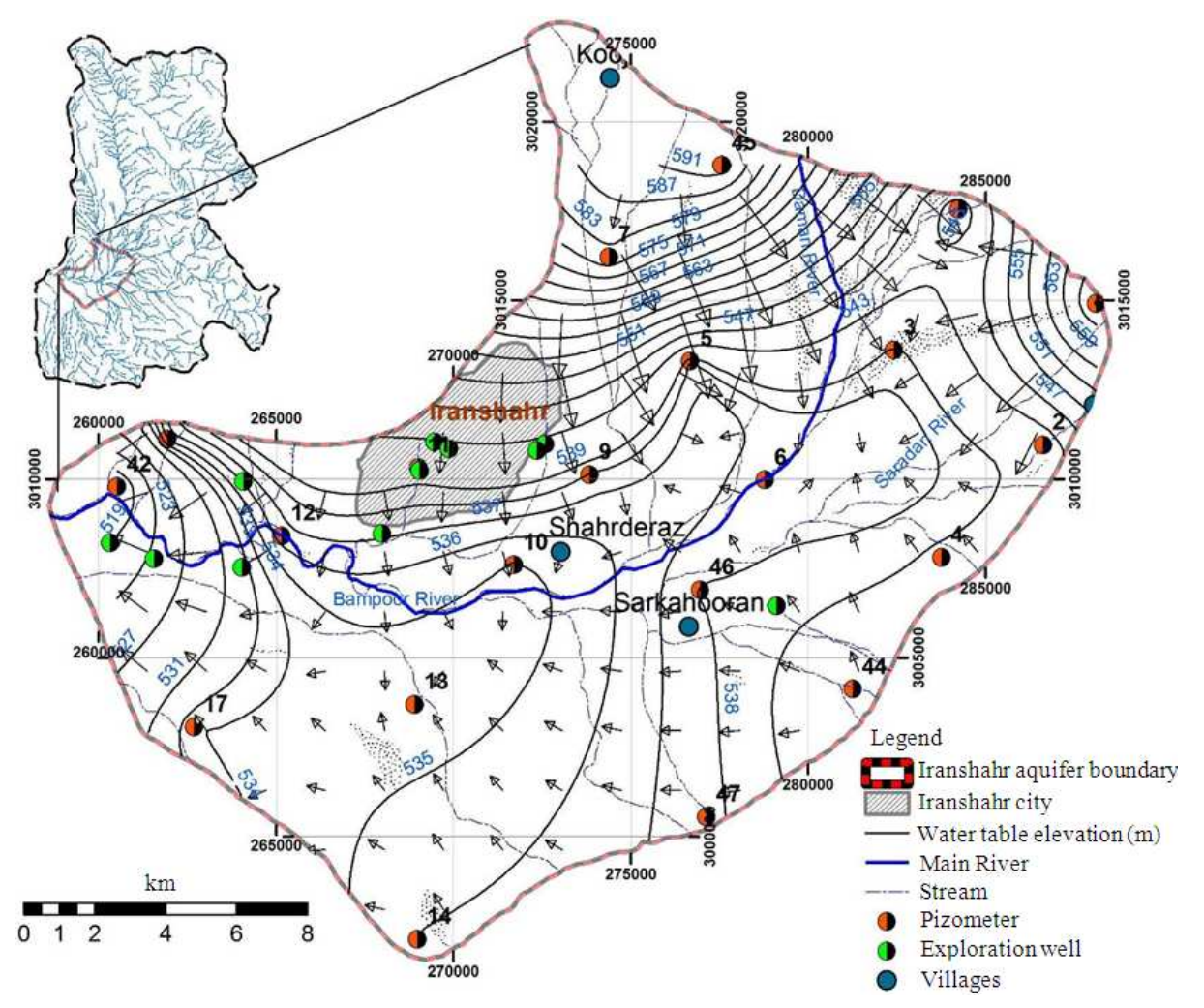

Fig. 3: Surface map of the Iranshahr Aquifer

There is some exploration points in the aquifer area on which transmisivity (T) and storage coefficient (S) were obtained by using pumping tests (Fig. 3). Alluvial thickness varies from $50 \mathrm{~m}$. in the west to approximately $250 \mathrm{~m}$. in the center part of the aquifer near Sarkahoran village (Fig. 3). Alluvial thickness in the north and east of the aquifer is about 120-150 meters. Groundwater depth is about $85 \mathrm{~m}$. in the east and decreases to near $5 \mathrm{~m}$. and less to the west, where groundwater begins to drain into the Bampour River outside of the model area. Fluctuations of the water table were measured monthly using 21 observation wells (Fig. 3) and were later used for model calibration.

Groundwater flow of the Iranshahr aquifer has been simulated using MODFLOW-2000. The Iranshahr aquifer consists of an unconfined layer. To prepare the conceptual model, geological information, drilling logs, exploration logs, pizometeric data and other information has been used. After construction of the conceptual model for calibration, head observation during one year (12 months) has been used as 12 stress periods. Hydraulic conductivity and specific yield zones were designed by using pumping experiments and exploration well drilling logs. One recharge zone was considered at the surface of the aquifer for direct recharge. The input and output boundaries were simulated using the General Head Boundary (GHB) package.

The selected simulation time are 12 successive months (12 stress periods) with 21 head observations at the end of each stress period. Totally, 252 head observation data were used in the calibration stage, which are observation data. The simulation was run for both transient and steady-state simultaneously.

\section{DISCUSSION}

During calibration condition many variables of the aquifer were considered as parameters and tried to estimate using automated calibration methods. Hydraulic conductivity and specific yield have been parameterized using simple zonation method. Totally, 31 parameters, including 5 hydraulic conductivity and 5 specific yield of five different zone, 3 recharge at 3 precipitation stress periods, one hydraulic conductance parameter of river bed in the outlet of the aquifer, 12 parameters of water withdrawal from the exploitation wells, 4 hydraulic conductance parameters of groundwater inflow and 1 conductance parameters of groundwater outflow, entered into a regression by 
means of the 228 observations of hydraulic heads. Calibration is accomplished iteratively, using nonlinear regression to estimate the value of different parameters. The iterative parameter estimation procedure was initialized by an initial estimate of the parameters of interest based on geological and hydrogeological information of the aquifer. These values were improved in each iteration to reproduce the observed values. Some useful guidelines for effective model calibration using nonlinear regression method were used to obtain the optimal value of parameters.

After calibration, optimized values of parameters were obtained 24 parameters were estimated by means of the regression and the rest un-estimated parameters were optimized using the trial-and-error method. Reasonableness of the estimated parameters, composite scaled sensitivity, correlation coefficients and all statistics mentioned and recommended by Hill (1998) were used for the optimization of the aquifer's parameters. The resulting objective function value (sum of squared difference between simulated and observed value) is $30.35 \mathrm{~m}^{2}$. The normality of the results is important to use of parameter uncertainty.

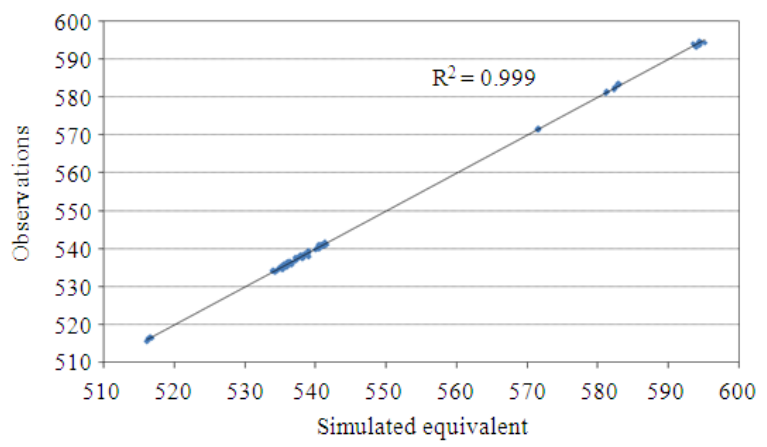

Fig. 4: Simulated values versus observed values

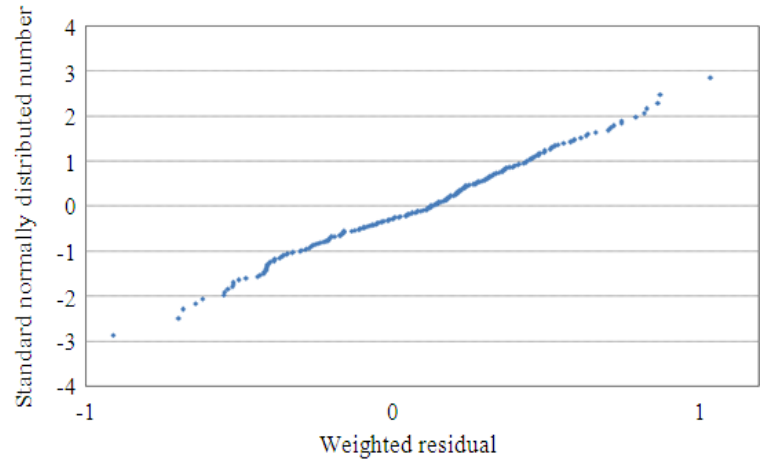

Fig. 5: Normal probability graph of residuals
The normal probability graph (Q-Q plot) of the residuals is shown in Fig. 3. The points would be expected to fall along a straight line if the residuals were both independent and normally distributed. A graph of simulated values versus observed values is shown in Fig. 4. It is expected the points are scattered around a line with slope one. Correlation coefficient of the obtained line is 0.99 which is suitable. During the calibration stage, zonation of hydraulic conductivity and specific yield changed with reasonable values to obtain the best fit between observed and simulated heads. Figure 5 show the final zonation and values of hydraulic conductivity and specific yield. As shown in the Fig. 6 specific values range between 0.1 and 0.23 and hydraulic conductivity range between 4.3 and $110 \mathrm{~m} \mathrm{day}^{-1}$.

\section{CONCLUSION}

Groundwater models especially with automated calibration capability are good tools for identifying hydraulic parameters such as hydraulic conductivity and specific yield. To prepare the conceptual model of Iranshahr aquifer, geological information, drilling logs, exploration logs, pizometric data and other information have been used and the groundwater flow was simulated by using MODFLOW-2000. The results of the model show a good fit of observation and simulated values. Hydraulic parameters of the aquifer have been estimated by using the automated calibration procedure. Optimized values and zonation of the hydraulic parameters of the aquifer indicate that the best area for development and extraction of groundwater of the aquifer are zones 3 and 4 respectively regarding the optimization of hydraulics values (Fig. 6).

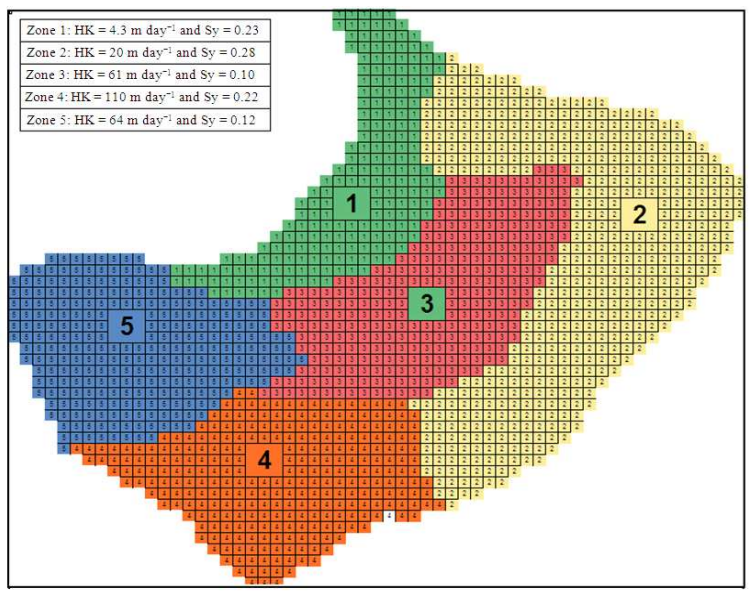

Fig. 6: Final zonation and values of hydraulic conductivity and specific yield 
Am. J. Environ. Sci., 6 (6): 477-483, 2010

\section{ACKNOWLEDGMENT}

This study is dedicated to the memory of the founder of Kerman University, Mr. Alireza Afzalipour, on the occasion of the centenary of his birth. The authors would like to express their appreciation to Water Research Committee of Sistan and Baluchestan Province for its support by Grant 105/86/M (SIW-86002) on $86 / 1 / 12$. This study has greatly benefited from the changes suggested by two anonymous reviewers.

\section{REFERENCES}

Abbasnejad, A. and R. Derakhshani, 2010. Identification of hidden karst lithology based on hydrogeochemical criteria: Chah-darya of rafsanjan (se Iran) as a case study. Am. J. Sci. Res., 12: 36-44. ISSN: 1450-223X

Abbaspour, K.C., R. Schulin and M.T. van Genuchten, 2001. Estimating unsaturated soil hydraulic parameters using ant colony optimization. Adv. Water Resour., 24: 827-841. DOI: 10.1016/S03091708(01)00018-5

Alipour, M. and R. Derakhshani, 2010. Identification of hydrogeological properties using the results of the groundwater modeling. Res. J. Environ. Toxicol., 4: 67-76. DOI: $10.3923 /$ rjet.2010.67.76

Al-Rababa, K.S., 2005. By-pass devices as effective means of protection from the hydraulic hammer. Am. J. Applied Sci., 2: 539-541. DOI: 10.3844/.2005.539.541

Anderson, M.P. and W.W. Woessner, 1992. Applied Groundwater Modeling Simulation of Flow and Advective Transport. Academic Press, San Diego, CA., pp: 381.

Cooley, R.L., 2004. A Theory for Modeling GroundWater Flow in Heterogeneous Media. US Geological Survey Professional paper 1679, ISSN: 1044-9612

D’Agnese, F.A., G.M. O`Brien, C.C. Faunt, W.R. Belcher and C. Sun Juan, 2002. A three dimensional numerical model of predevelopment conditions in the Death Valley regional ground-water flow system, Nevada and California. US Geological Survey Water-Resources Investigation Report 024102, pp: 114. http://pubs.usgs.gov/wri/wri024102/pdf/WRIR024102.pdf

Derakhshani, R. and M. Alipour, 2010. Remediation of acid mine drainage by using tailings decant water as a neutralization agent in sarcheshmeh copper mine. Res. J. Environ. Sci., 4: 250-260. DOI: 10.3923/rjes.2010.250.260
Donaldson, J.R. and R.B. Schnabel, 1987. Computational experience with confidence regions and confidence intervals for nonlinear least squares. Technometrics, 29: 67-87. http://www.jstor.org/pss/1269884

Emami, M.H., 2000. Magmatism in Iran. Geological Survey of Iran (G.S.I), No. 79, pp: 608. ISBN: 9646178-01-4.21

Farhoudi, G. and D.A. Karig, 1977. Makran of Iran and Pakistan as an active arc system. Geology, 5: 664-668. DOI: $10.1130 / 0091-$ 7613(1977)5<664:MOIAPA>2.0.CO;2

Gardner, P.M., 2009. Three-dimensional numerical model of ground-water flow in Northern Utah Valley, Utah County, Utah: U.S. Geological Survey Scientific Investigations. http://pubs.usgs.gov/sir/2008/5049/pdf/sir20085049.pdf

Hadavi, F., 2002. The calcareous nannofossils of Iran. Koppedagh, central of Iran, Makran, Geological Survey of Iran (G.S.I), No. 83, ISBN: 964-617807-3.

Harbaugh, A.W., E.R. Banta, M.C. Hill and M.G. McDonald, 2000. MODFLOW -2000, The U.S. Geological Survey modular ground-water model - User guide to modularization concepts and the ground-water flow process. U.S. Geological Survey Open-File Report 00-92, pp: 121. http://pubs.er.usgs.gov/usgspubs/ofr/ofr200092

Hill, M.C. and C.R. Tiedeman, 2007. Effective Groundwater Model Calibration: With Analysis of Data, Sensitivities, Predictions and Uncertainty. John Wiley and Sons, Inc., New York, USA., pp: 455.

Hill, M.C., 1998. Method and guidelines for effective model calibration. U.S. Geological Survey WaterResources Investigations Report 98-4005, pp: 90. http://pubs.er.usgs.gov/usgspubs/wri/wri984005

Hill, M.C., E.R. Banta, A.W. Harbaugh and E.R. Anderman, 2000. MODFLOW-2000, the U.S. Geological Survey modular ground-water model, User guide to the observation, sensitivity and parameter estimation process and three post-processing programs: U.S. Geological Survey Open-File Report 00-184, pp: 209. http://pubs.er.usgs.gov/usgspubs/ofr/ofr00184

Jolgaf, M., S.B. Sulaiman, M.K.A. Ariffin and A.A. Faieza, 2008. Closed Die Forging Geometrical Parameters Optimization for Al-MMC. Am. J. Eng. Applied Sci., 1: 1-6. DOI: 10.3844/.2008.1.6

Madsen, H., 2003. Parameter estimation in distributed hydrological catchment modeling using automatic calibration with multiple objectives. Adv. Water Resources, 26: 205-216. DOI: 10.1016/S03091708(02)00092-1 
McCall, G.J.H., 1985. Explanatory text of the Pishin quadrangle map 1:250000. Ministry of Mines and Metals, Geological Survey of Iran, pp: 295.

Naeser, H., 2005. Conservation of "Partial Vorticity" with application on hydraulic jumps. Am. J. Applied Sci., 2: 1194-1197. DOI: 10.3844/.2005.1194.1197

Opafunso, Z.O., I.I. Ozigis and I.A. Adetunde, 2009. Pneumatic and hydraulic systems in coal fluidized bed combustor. Am. J. Eng. Applied Sci., 2: 88-95. DOI: $10.3844 / .2009 .88 .95$

Poeter, E.P. and M.C. Hill, 1997. Inverse models: A necessary next step in groundwater modeling. Groundwater, 35: 250-260. DOI: 10.1111/j.17456584.1997.tb00082.x

Rahmat, M.F., S.M. Rozali, N.A.W. Zulfatman and K. Jusoff, 2010. Modeling and controller design of an electro-hydraulic actuator system. Am. J. Applied Sci., 7: 1100-1108. DOI: 10.3844/.2010.1100.1108

Rahnama-Rad, J., R. Derakhshani, G. Farhoudi and H. Ghorbani, 2008. Basement faults and salt plug emplacement in the arabian platform in Southern Iran. J. Applied Sci., 8: 3235-3241. DOI: 10.3923/jas.2008.3235.3241
Romanko, A.E., 2006. New data on cenozoic subalkaline rocks of eastern iran. Doklady Earth Sci., 404: 1037-1040. http://rogov.zwz.ru/Romanko,2005_Cenozoic_Iran .pdf

Solomatine, D.P., Y.B. Dibike and N. Kukuric, 1999. Automatic calibration of groundwater models using global optimization techniques. Hydrological Sci. J., $\quad 44$ : $879-894 . \quad$ DOI: $10.1080 / 02626669909492287$

Stocklin, J., J. Eftekharnezhad and A. Houshmandzadeh, 1972. Central Lut Reconnaissance East Iran. Geological Survey of Iran, Rep. No. 22, pp: 54.

Suhail, A.H., N. Ismail, S.V. Wong and N.A. Abdul Jalil, 2010. Optimization of cutting parameters based on surface roughness and assistance of workpiece surface temperature in turning process. Am. J. Eng. Applied Sci., 3: 102-108. DOI: 10.3844/.2010.102.108

Tiedeman, C.R., D.M. Ely, M.C. Hill and G.M. O'Brien, 2004. A method for evaluating the importance of system state observations to model predictions, with application to the death valley regional groundwater flow system. Water Resources Res., 40: 12411-12414. DOI: 10.1029/2004WR003313 